\section{A cultura Blog: questões introdutórias ${ }^{1}$}

\author{
RESUMO
}

Aos mais "integrados", o fenômeno Blog (ou Weblog) tem sido considerado demonstração positiva da evolução da cultura da internet. Tratando-se de ferramentas de publicação on-line os blogs, há alguns anos, têm assumido o papel de noticiar visões individuais (e de pequenas coletividades), locais e especializadas sobre diversos temas. Entre os assuntos mais publicados estão as vidas privadas de seus próprios autores (blogueiros). Porém, longe de ser apenas espaço de construção e de representação de identidades individuais, este formato serve estrategicamente às produções small media. Os signos relacionados aos (e nos) Blogs falam muito mais que somente das possibilidades técnicas desta ferramenta: não só o meio é a mensagem como são também todo seu contexto e produtores.

\section{ABSTRACT}

To the most integrati, the Blog (or weblog) phenomenon has been considered a positive demonstration of culture evolution in Internet. Being on-line publication tools, Blogs have assumed the function of notifying individuals (and small collectives as well) about perceptions, places and specialized opinions on diverse subjects. One of the most popular subject matters is the private lives of their authors, the bloggers. However, far from being just a space for identity construction and representation, they strategically serve as a small media for colective productions. The signs related to blogs speak much more than just about the technical possibilities of this tool: the medium is not only the message but the context and producers as well.

\section{PALAVRAS-CHAVE (KEY WORDS)}

- Cultura e Comunicação (Culture and Communication)

- Tecnologia e Sociedade (Technology and Society)

- Weblogs

\section{Carolina Rodrigues Paz}

Profa.das Faculdades Integradas ASSESC FASSESC e do Instituto de Ensino Superior da Grande Florianópolis - IES. Laboratório de Ensino a Distância - LED/UFSC

\section{Introdução}

A EXPERIMENTAÇÃO, sem precedentes na história humana, da aceleração e flexibilidade crescentes do espaço e tempo, as várias "globalizações" (econômicas, políticas, culturais), as articulações em rede entre diversos grupos sociais espalhados pelo mundo, são fenômenos socioculturais comumente atribuídos à torrente de inovações tecnológicas que irrompe o cotidiano.

Importantes teóricos, das várias áreas da ciência, acreditam que as inovações tecnológicas determinam mudanças culturais. Castells (1999), por exemplo, afirma que o surgimento de um novo sistema de comunicação global "está mudando e mudará para sempre nossa cultura", atribuindo às tecnologias da comunicação a recente e grande revolução cultural a elas associada.

Não se pode negar a influência que os recursos tecnológicos exercem sobre sociedades e culturas mas, longe de crer no alcance explicativo da noção de "impacto tecnológico", o determinismo subentendido nesta expressão é que deve ser negado. Assim, considera-se que na relação cultura-sociedade-tecnologia há uma interpenetração de influências e que essa terceira componente - a tecnologia ora pode influenciar, ora está subordinada à sociedade e à cultura onde aparece e se difunde ${ }^{2}$.

Talvez seja mais interessante, levando em conta a complexidade do tema, tentar explicar tais mudanças segundo a ótica de Giddens (1991), que as atribui à modernidade, ou seja, a todo um movimento sociocultural historicamente localizado. Este autor fornece dois importantes conceitos para o entendimento sobre a atualidade: 
desencaixe e reflexividade. $O$ primeiro refere-se ao '“deslocamento' das relações sociais de contextos locais de interação e sua reestruturação através de extensões indefinidas de tempo-espaço"; o segundo se caracteriza no fato de que "as práticas sociais (modernas) são constantemente examinadas e reformadas à luz de informação renovada sobre estas próprias práticas, alterando assim constitutivamente seu caráter" (GIDDENS, 1991, p. 29 e 45).

Então, é possível afirmar que as novas tecnologias da informação e da comunicação (NTIC) são uma expressão de tais fenômenos sociais, pois são em si mesmas patrocinadoras de "desencaixe"; e, através delas, como em outras circunstâncias modernas, ocorre a renovação das práticas sociais através da atualização constante de informações, ou seja, desenvolve-se a "reflexividade".

Portanto, sem desconsiderar a pertinência da evolução tecnológica nas transformações sociais, é importante observar a grande capacidade e o interesse humanos em flexibilizar de forma ampla suas possibilidades de relações e seus meios de conhecer o mundo.

A internet, enquanto meio de manifestação e representação desses "fenômenos modernos", pode ser tomada como "uma das mais importantes inovações tecnológicas da história, resultado e causa de profundas e definitivas transformações sociais" (PAZ, 2003, p. 23). Nela encontram-se representadas, senão todas, pelo menos a maioria das estruturas sociais e dos fenômenos encontrados no "mundo real", manifestados através do crescente conjunto de ferramentas e linguagens constantemente inventadas, reproduzidas e renovadas. Entre estas se encontram os weblogs.

Fenômeno de comunicação, evolução da internet, moda na web, "coisa de nerd", são alguns dos rótulos dados aos weblogs (ou blogs, simplesmente) por um certo número de usuários pouco mais "especializados" do que o "simples navegante". Tais classificações revelam o quanto a ferramenta e suas apropriações vêm despertando o interesse explicativo entre seus usuários e observadores (pesquisadores, jornalistas, técnicos, etc.). ${ }^{3}$

Apesar das diversas manifestações quanto a sua importância, este objeto ainda é carente de um tratamento científico, principalmente por parte das ciências sociais. Por isso, atendo-se menos às características técnicas da ferramenta, a proposta neste artigo é trazer ao campo das pesquisas em comunicação e cultura alguns aspectos e considerações relacionados à apropriação social dessa tecnologia e seus conseqüentes resultados. Fazendo referência a textos e imagens de alguns blogs, observando e analisando seus usos é possível perceber manifestações relativas ao "culto da pessoa comum"; à apropriação local da ferramenta enquanto small media; e a sua potencialidade de formar e catalisar comunidades.

\section{Aparecimento e apropriações}

Cada vez mais popular entre os usuários ${ }^{4}$ da internet, o blog é um formato de publicação on-line que desperta interesse por suas ditas simplicidade e facilidade de uso. Servindo a diversos tipos de sites (pessoais, notícias, intranets corporativas, etc.) os blogs são diários on-line, que reúnem uma coleção de textos, cujo conteúdo é um conjunto de mensagens (posts) publicadas instantaneamente na web, usualmente curtas e organizadas cronologicamente.

Segundo Jonkatz (2000), weblog não é um termo novo na internet, seu uso que o é. O que era a priori um arquivo de registros de atividades realizadas num servidor web começou, com o tempo, a ser ressignificado através de novos usos fazendo com que se tornasse mais conhecido como sinônimo de "diário on-line", servindo para "incrementar" os sites especializados e idiossincráticos que já existiam há alguns anos. 
Em 1998, afirma Blood (2003), já existia um certo número de sites do tipo dos que agora são identificados como blogs. Um dos pioneiros, segundo a autora, é o Infosite (www.jjg.net/infosite/) que, em 1998, não passava de uma lista de sites favoritos compilada por Jesse James Garrett. Então, em julho de 1999, surge o primeiro serviço gratuito "construa seu próprio blog", o Pitas (www.pitas.com), e, em agosto do mesmo ano, aparece o Blogger (www.blogger.com), desenvolvido pelo Pyra Labs, o qual se tornou um dos mais conhecidos e reconhecidos serviços deste tipo ${ }^{5}$.

A facilidade da publicação (em relação principalmente às linguagens de programação) acessível aos usuários leigos deve-se ao fato de que ela acontece através de ferramentas baseadas na web. Estas possibilitam edição e atualização instantânea dos conteúdos, sem que haja necessidade do usuário dominar linguagens e ter que fazer uso de outros softwares, como, por exemplo, os de transferência de arquivos entre computadores e servidores. $\mathrm{Na}$ realidade, para se ter um blog não é necessário ter conta num servidor, pois a maioria desses serviços disponibiliza gratuitamente espaços para hospedagem das páginas de seus usuários ${ }^{6}$.

Em poucos minutos, preenchendo um cadastro, qualquer um pode criar sua página através de alguns templates (modelos) a sua escolha com os quais é possível definir com facilidade o layout de como os posts serão exibidos, indicando quais dados (data, hora, autor, e-mail, etc.) serão disponibilizados, a ordem com que aparecerão (começando do post mais recente ao mais antigo, por exemplo), quantos posts serão exibidos por página, entre outras opções.

O grau de complexidade e especificidade de conteúdos e de sofisticação técnica do blog depende da finalidade do site e do conhecimento técnico do usuário. Hoje, são quase tão comuns quanto os serviços para publicação de blogs, outros tantos serviços que disponibilizam ferramentas para comentários de posts ${ }^{7}$. Assim, os visitantes e leitores de um blog podem se mostrar neste espaço através de comentários sobre os conteúdos dos posts publicados.

Contudo, usuários e grupos que têm um conhecimento mais aprofundado sobre programação web podem adaptar outros recursos aos seus blogs ou desenvolver suas próprias ferramentas independente dos serviços disponíveis, fazendo uso das várias linguagens web para o desenvolvimento de ambientes deste tipo.

\section{Idolatria dos comuns}

Assim como acontece através dos polêmicos reality shows, os blogs servem muito ao cultivo de individualismos exacerbados e à idolatria da "pessoa comum". Em vários blogs são comuns as práticas de diluição entre o público e 0 privado tornando o diário íntimo acessível a quem queira saber mais sobre a "vida real" de quem o escreve.

Nas sociedades pós-modernas, afirma Baudrillard $(1973)^{8}$, o privado está transformado em simulação da privacidade "real", numa hiper-realidade. Preferese a reprodução técnica (simulacro) da realidade, intensificando-a, e tal simulação passa a ser "mais real" que a própria realidade empírica ${ }^{9}$. Assim como nos reality shows, onde, entre telespectadores e jogadores, existem as câmeras (o meio), no caso dos blogs há o computador conectado à rede ligando autores e leitores. O blogueiro representa-se através de uma interface "customizada", de textos e de imagens escolhidos, manipuláveis, que fazem do autor personagem, de forma parecida à reprodução da "vida real" dos atores/personagens de um "Big Brother" que é exibida através de planos de câmera, edições e trilha sonora.

Quanto maior a saturação do real praticada na hiper-realização do privado, 
tornando-o um espetáculo, geralmente maior é a audiência. Mesmo diferente de um fenômeno de massa, visto que os públicos dos blogs são mais específicos e, talvez, menos "homogeneizáveis", pode-se verificar a reprodução dessa mesma lógica.

A popularidade dos "reality blogs" está, conforme se observou, intimamente ligada à habilidade do autor de organizar realidades e representar-se através de personagens com os quais o público pode identificar-se, não necessariamente por equivalência, mas como forma de uma realização transgressora. Segundo Durand (apud JOLY, 1996), figuras de retórica (hipérboles, elipses, metáforas, etc.) podem provocar prazer, através de transgressões fingidas (até porque a veracidade, neste caso, não é importante), permitindo que o "consumidor" sonhe com um mundo onde tudo é possível.

Contudo, o espaço virtual, afirma Featherstone (1996), não só possibilita a simulação de pessoas e coisas do "mundo real" no "mundo virtual", como facilita sua desconstrução e reconstrução a fim de criar novas imagens e mundos e, assim, dinamicamente (e sempre em relação) autores e leitores refazem seus mundos virtuais, reais, quando possível, e a si mesmos (fazendo, assim, que se retorne ao conceito de reflexividade giddeniano).

\section{Manifestações small media}

Uma contribuição inegável dos "blogueiros", pelo menos de alguns, é a atualização constante de informações sobre diversos temas. São muitos os blogs que adquiriram status de noticiários. Essa apropriação da tecnologia (não só da internet, mas também de outras mídias), que coloca nas mãos do público a possibilidade de pulverizar o controle sobre a produção de informação e notícias, enquadra-se no que se entende por small media, ou seja, uma nova dimensão no conjunto dos meios de comunicação diferente do mass media.
"Today, via the Internet, where users as well as creators of web sites can contribute news, members of the public are often performing the jobs traditionally reserved for the media. This is but the latest breakthrough in technology which has helped pluralize control of the media.

As technology improves, it generally gets easier to learn how to wield the tools of the trade. At the same time, costs of setting up a news service have overall dropped. Small TV, radio, print and online news outlets have proliferated." (UNESCO, 2000, p.17)

Se a relação tradicional dos meios de comunicação de massa é de um emissor para um conjunto de inúmeros receptores (quantidade ainda mais difícil de dimensionar no caso da internet) para o small media esta relação se aproxima muito mais da relação face a face, pelo simples fato dos emissores estarem próximos (se não for localmente, pelo menos, culturalmente) e muitas vezes interagindo (por vezes, quase que intimamente) com os receptores.

No caso dos blogs, isso é visível, tanto em sites pessoais que esporadicamente discutem ou relatam acontecimentos cuja importância é de interesse público, assim como naqueles que propõem tratar de temas específicos (música, cinema, jornalismo, sexo, humor, etc.) que não da vida privada do autor blogueiro. Como exemplo do primeiro caso há o blog de Cristiano Dias (www.crisdias.com) que se viu personagem do drama pelo qual passou Nova lorque com os atentados ao World Trade Center, em 11 de setembro de 2001. Seus posts serviram para manter informados amigos, familiares e tantos outros que não conseguiam informações junto às agências oficiais de notícias devido aos congestionamentos técnicos causados pelo excesso de demanda que dificultavam a circulação dos dados. Um segundo exemplo é o blog "Assessorindie" 
(www.flaviadurante.com/assessorindie) da jornalista Flávia Durante que traz matérias sobre bandas, festas, shows, entre outros assuntos referentes ao circuito de música "alternativa" brasileira. Flávia também mantém um blog sobre sua vida "privada", o "C:/Blah Blah Blog" (www.flaviadurante.com/ blog).

Portanto, pelo fato de hoje conviver-se com outros tipos de mídias que não podem mais ser chamadas "de massa" é que Santaella (1992) propõe um entendimento do que seja a "cultura das mídias" diferenciado-a da "cultura de massas". Por cultura das mídias tem-se:

"A cultura que nasce nos trânsitos, intercâmbios, fricções e misturas entre os diferentes meios de comunicação, produzindo como conseqüência um movimento constante de transformação nas formas tradicionais de produção de cultura, eruditas e populares, assim como nos processos de produção e recepção da cultura de massas" (Santaella, 1992, p.08).

Neste sentido, a autora defende a hipótese de que quanto mais cresce o conjunto das mídias, em número e em diversidade, mais crescem a movimentação e a interação entre diversas formas culturais dinamizando assim as relações entre os agentes da comunicação e da produção cultural. Tal dinâmica se justifica pela produção de resíduo informativo (visto que uma das características fundamentais da cultura das mídias é a ênfase dada à informação) e pela mistura de vários códigos e processos sígnicos. Estas ampliam as possibilidades de leituras mais diversificadas por parte dos receptores sobre uma mesma notícia. Isto faz com que ainda mais textos e interpretações sejam trocados nos "processos orquestrais de comunicação" (Winkin, 1998) ${ }^{10}$.

Comunidades blogueiras
Nos tempos atuais, afirma Castells(1999), onde sociedades encontram-se cada vez mais fragmentadas devido às identidades cada vez mais específicas e difíceis de compartilhar, é significante o esforço por manter uma rede de comunicação que aproxime as individualidades para a construção de identidades coletivas:

“(...) a comunicação simbólica entre os seres humanos e o relacionamento entre esses e a natureza, com base na produção (e seu complemento, o consumo), experiência e poder, cristalizam-se ao longo da história em territórios específicos, e assim geram culturas e identidades coletivas" (Ibid., 1999, p. 33).

Em outras palavras, o que Castells descreve são sociedades nas quais o desencaixe, conforme conceituado por Giddens, das identidades mais individualizadas que coletivas pede por um esforço de reaproximação que pode ser atingido através de uma rede de comunicação. Nesse sentido, tais individualidades são reunidas gerando coletividades, sendo a formação de comunidades um exemplo.

No contexto das comunidades virtuais ${ }^{11}$, afirma Jonkatz (2000), o blog é uma novidade envolvente. Enquanto ferramentas de comunicação, os blogs têm servido à formação de pequenos grupos on-line, reunindo na internet equipes de trabalho, famílias, grupos de amigos, entre outros, tornando-se uma alternativa à formação de fóruns de discussão diferentes dos existentes via correio eletrônico.

Assim, blogs de enfoque jornalístico, educacional, corporativos surgem como possíveis catalisadores da integração e do diálogo entre indivíduos (autores ou comentaristas) num mesmo espaço (site) ou compondo uma rede de blogs, "redes de confiança", quando fazem referência entre si, implícita ou explicitamente. 


\section{Conclusão}

Os limites para a continuidade da técnica estão relacionados com sua capacidade de ser adaptada através de seu uso. A internet desde sua invenção até os dias atuais sofreu e vem sofrendo inúmeras modificações. Caso não tivesse assim evoluído, estaria extinta ou ainda servindo apenas aos interesses militares que patrocinaram sua criação. Acredita-se, devido a sua capacidade de responder perfeitamente às necessidades de comunicação a distâncias síncrona e assíncrona, que esta tecnologia deixou de ser exclusividade de uma instituição e passou a ser incorporada por outros setores da sociedade.

Os diversos usos da internet fazem com que novas ferramentas apareçam ou que antigas sejam renovadas, num ciclo contínuo de construção e apropriação social que caracteriza tudo o que seja tecnologia e que, muitas vezes, certamente, toma caminhos nunca pensados quando da sua criação. Assim, a tecnologia por ela mesma não iria muito longe se não fosse seu caráter social que pode lhe conferir a capacidade de adaptar-se às necessidades sociais, estendendo suas possibilidades de continuar existindo até que haja uma quebra de paradigma e uma inovação socialmente aceita a torne obsoleta. $O$ uso reconstrói e ressignifica, a exemplo do weblog, que de simples registro de atividades realizadas num servidor tornouse poderosa ferramenta integradora e reprodutora de relações sociais.

Além disso, é importante lembrar que a análise apenas sobre a ferramenta já diz muito sobre a sociedade que a forjou e que seus usos, enquanto manifestações sígnicas, são representações de importantes fenômenos sociais, muitos já existentes antes mesmo do aparecimento da internet.

Assim, este artigo veio apenas apontar alguns dos recortes possíveis para pesquisas em ciências sociais (sociológicas, etnológicas, semiológicas) cujo objeto ou contexto de análise seja o universo dos blogs. As continuidades possíveis são muitas e, certamente, sabendo que este texto será de diversas formas interpretado e apropriado, serão vários seus desdobramentos não imaginados aqui .

Notas

1 Texto originalmente apresentado no VII Seminário Internacional da Comunicação - Da Aldeia Global ao Ciberespaço: A Tecnologias do Imaginário Como Extensões do Homem, PUCRS, Porto Alegre (RS), agosto, 2003.

2 Para um maior desenvolvimento da crítica à noção de impacto ver Benakouche (1999) e Paz e Benakouche (2002).

3 Existem diversos textos na web onde usuários, "blogueiros" ou não, especulam sobre as características revolucionárias e potencializadoras de evolução midiática trazidas pela ferramenta. Dentre vários, pode-se citar os mesmos blogs apresentados neste artigo.

4 Neste artigo convencionou-se entender por usuário aquele indivíduo cujos conhecimentos sobre a tecnologia o tornam minimamente capaz de atuar ativamente no ciberespaço, diferente daquele cujas condições técnicas 0 limitam apenas a "assistir" às diversas manifestações processadas neste meio.

5 No Brasil, quase todos os portais como Uol (www.uol.com.br), IG (www.ig.com.br), Globo.com (www.globo.com), entre outros, oferecem o serviço. A Globo.com, por exemplo, é detentora dos direitos sobre a versão nacional do Blogger (www.blogger.com.br).

6 Um exemplo é o Blogspot (www.blogspot.com) oferecido pelo Blogger.

70 "Falou \& Disse" (www.falouedisse.com), por exemplo.

8 Ao contrário de Giddens, Baudrillard, como membro 
da escola pós-moderna, defende que transformações ocorridas nesta "sociedade pós-industrial" são de caráter diverso ao projeto moderno de sociedade. Em seu discurso, defende argumentos que trazem 0 conceito do hiper-real, ou seja, um simulacro mais atraente e repleto de signos que se torna mais "real" que a própria realidade. Apesar de estar-se mencionando aqui a discussão sobre 0 que seja a modernidade e pós-modernidade, ela é muito extensa e possível de ser tratada como tema exclusivo de várias teses. Esta não cabe e não será tratada neste artigo.

9 Um exemplo, para um entendimento do que seja essa simulação do real, é a fotografia publicitária que transforma a imagem do produto "mais real" e "satisfatória" do que este é na realidade.

10 Winkin defende 0 uso do modelo orquestral de comunicação proposto pelos autores do Colégio Invisível em detrimento do modelo processual (telegráfico) de Shannon, pois o primeiro, diferentemente deste último, entende 0 indivíduo como agente do processo de comunicação (intérprete e autor) e não só como receptor passivo.

110 conceito de comunidade virtual foi popularizado por Rheingold (1998), o qual descreve comunidades virtuais como sendo "agregações sociais que emergem da Rede quando um determinado grupo de pessoas prossegue com suas discussões durante um determinado período, com envolvimento suficiente, para formar redes de relacionamentos pessoais no ciberespaço".

\section{Referências}

BAUDRILLARD, Jean. 0 Sistema dos Objetos. São Paulo: Perspectiva, 1973.

BENAKOUCHE, Tamara. "Tecnologia e Sociedade: contra a noção de impacto tecnológico". In: Cadernos de Pesquisa, n. 17, CFH/UFSC, Florianópolis, set/1999.

BLOOD, Rebecca. "Weblogs: A History and Perspective". Disponivel em: <http://www.rebeccablood.net/essays/weblog history.html>. Acesso em: 10 de fevereiro de 2003.

CASTELLS, Manuel. A Sociedade em Rede: A Era da informação - economia, sociedade e cultura. v. 1, $3^{\text {a }}$ ed. São
Paulo: Paz e Terra, 1999.

FEATHERSTONE, Mike. "A Globalização da Complexidade : Pós-modernismo e cultura de consumo". In: RBCS, n. 32, ano 11, outubro/1996.

GIDDENS, Anthony. As Conseqüências da Modernidade. São Paulo: Unesp, 1991.

JOLY, Martine. Introdução à Análise da Imagem. Campinas: Papirus, 1996.

JONKATZ, Post. "Here Comes the Weblogs". In: Slashdotorg. Disponivel em: <www.directhop.com/cgi-bin/smartframe/ smartframe.cgi?http://slashdot.org/features/99/05/13/ 1832251.shtml>. Acesso em: 15 de julho de 2000.

PAZ, Carolina Rodrigues; BENAKOUCHE, Tamara. "Comunidade EJA On-line: um ambiente Web para integração de profissionais e pesquisadores da EJA". Anais. II TELECONGRESSO INTERNACIONAL DE EDUCAÇÃO DE JOVENS E ADULTOS, 2002. Disponível em <http: //www.idilica.com.br/projetos.html> Acesso em: 7 de setembro de 2002.

"Comunidade EJA On-line: Uma Proposta para Integração dos Profissionais e Pesquisadores da Educação de Jovens e Adultos (EJA) na Web". 2003. 100 f. Dissertação (Mestrado em Engenharia de Produção) - Curso de PósGraduação em Engenharia de Produção, Universidade Federal de Santa Catarina, Florianópolis.

RHEINGOLD, Howard. The Virtual Community (The Electronic Version). 1998. Disponivel em <http://www.rheingold.com/vcl book>. Acessado em 05 de março de 2002.

SANTAELLA, Lúcia. Cultura das Mídias. São Paulo: Razão Social, 1992.

UNESCO. "Small medias, new voices". The UNESCO Courier. Paris, n. 2, fevereiro, 2000. Disponível em: <http: //unesdoc.unesco.org/images/0011/001187/118789e.pdfs. Acessado em 05 de março de 2002.

WINKIN, Yves. A Nova Comunicação: Da Teoria ao Trabalho de Campo. Campinas: Papirus, 1998. 